\title{
Racial Differences in the Applicability of Bronfenbrenner's Ecological Model for Adolescent Bullying Involvement
}

\author{
Jun Sung Hong, Simon C. Hunter, Jinwon Kim, Alex R. Piquero, and Chelsey Narvey
}

\section{QUERY SHEET}

This page lists questions we have about your paper. The numbers displayed at left are hyperlinked to the location of the query in your paper.

The title and author names are listed on this sheet as they will be published, both on your paper and on the Table of Contents. Please review and ensure the information is correct and advise us if any changes need to be made. In addition, please review your paper as a whole for typographical and essential corrections.

Your PDF proof has been enabled so that you can comment on the proof directly using Adobe Acrobat. For further information on marking corrections using Acrobat, please visit http://journalauthors.tandf.co.uk/production/acrobat.asp; https://authorservices.taylorandfrancis.com/how-to-correct-proofs-with-adobe/

The CrossRef database (www.crossref.org/) has been used to validate the references. Changes resulting from mismatches are tracked in red font.

\section{AUTHOR QUERIES}

Q1 Citation [Roberts et al., 2009] has been updated. Please check.

Q2 Citation [Connell and Prinz, 2002] has been updated. Please check.

Q3 Citation [O'Moore and Kirkham, 2001] has been updated. Please check.

Q4 Please provide reference for citation [Haynie et al. 2001].

Q5 Please provide reference for citation [Swearer and Doll 2001].

Q6 Please provide missing [editor name or institutional editor name/page number] for [Currie et al., 2012].

Q7 Please cite [Larochette et al., 2010] in text or delete reference. 


\title{
Racial Differences in the Applicability of Bronfenbrenner's Ecological Model for Adolescent Bullying Involvement
}

\author{
Jun Sung Hong a, Simon C. Hunter ${ }^{\mathrm{b}}$, Jinwon Kimc, Alex R. Piquero', and Chelsey Narvey \\ aWayne State University, Detroit, MI, USA; bUniversity of Strathclyde, Glasgow, UK; 'Sungkyunkwan University, Seoul, \\ South Korea; dUniversity of Texas at Dallas \& Monash University, Richardson, TX, USA; eUniversity of Texas at Dallas, \\ Richardson, TX, USA
}

\begin{abstract}
Objectives: Social scientists have devoted much theoretical and empirical attention to studying the correlates of bullying perpetration and victimization. Much less attention has been devoted to studying race differences in the correlates of bullying behaviors despite the importance of these when designing effective and focused prevention and intervention programs.

Methods: Utilizing data from the 2009 to 2010 Health Behavior in SchoolAged Children (HBSC) study in the United States, this study applies Bronfenbrenner's ecological model to bullying in order to examine how various interrelated systems are associated with bullying perpetration, victimization, and their concordance in a nationally representative sample of adolescents.

Results: Findings shown important similarities, as well as some differences, across race in how key parental and peer relationships relate to aspects of involvement in bullying. Directions for future research are noted.
\end{abstract}

\section{ARTICLE HISTORY}

Received 18 April 2019

Accepted 7 October 2019

Bullying is a type of behavior that is repeatedly perpetrated by an individual or a group of individuals against a target (Gladden et al. 2014). Recent national data indicate that in 2017, about $20 \%$ of students (ages 12-18) reported being bullied during the school year; of those who reported being bullied, about $41 \%$ thought bullying would occur repeatedly (Musu-Gillette et al. 2019). The prevalence of bullying, coupled with high levels of maladjustment that it is associated with, has led to widespread anti-bullying efforts (Birkland and Lawrence 2009; Hall 2017). Anti-bullying programs have been widely developed and their effectiveness has been tested (Gaffney, Farrington, and Ttofi 2019; Merrell et al. 2008; Scherr and Larson 2010; Ttofi and Farrington 2011). According to the Bureau of Justice Statistics, $75.5 \%$ of public schools provide some form of training to teachers and aides in recognizing bullying (Zhang, Musu-Gillette, and Oudekerk 2016). Despite these efforts, findings have been inconsistent (Ferguson et al. 2007; Hall 2017). Several studies evaluating a widely used anti-bullying program in U.S. schools have reported positive results (Black and Jackson 2007; Limber et al. 2004). However, one study on the effectiveness of this program in 10 public middle schools reported that victimization decreased among Whites, but no similar effects were found for other racial groups (Bauer, Lozano, and Rivara 2007). This may be, in part at least, because there is little understanding of the different causes and processes underpinning the use and experience of bullying across different racial groups. Significant differences exist between Black and White youth with respect to a number of different risk factors. Black youth are more likely to reside in disadvantaged neighborhoods, have compromised familial situations, be exposed to violence, and have limited educational opportunities and attainment (Piquero 2015; Wilson 1987). As a result, 
bullying programs that do not pay attention to these differences and incorporate them into programmatic efforts will likely not have the same effect on Blacks as on Whites.

Implementing best practices for bullying requires a comprehensive understanding and description of bullying and victimization risks across racially diverse youth. Scholars have proposed an ecological approach to assessing factors related to the risk that certain youth have to be involved in bullying (Shetgiri, Lin, and Flores 2013; You, Kim, and Kim 2014) as well as an ecologically based prevention strategy (Espelage 2004). The central tenet of the ecological perspective is that adolescent development is shaped by the ongoing qualities of various social settings in which the youth is embedded (Bronfenbrenner 1979). While a large percentage of school districts provide bully-recognition training to teachers, Bronfenbrenner's $(1979,1994)$ perspective underscores the importance of recognizing the quality of teachers and conditions of schools that might differ across individuals, specifically those who are Black and are more likely to come from a lower socioeconomic status (SES) background. Moreover, Black and White youth differ in their accumulated exposure to multiple environmental risk factors (Piquero 2015). This accumulated exposure is crucial to understand the different needs that individuals might have.

In particular, adolescents differ in their susceptibility toward environmental influences, both positive and negative (Belsky, Bakermans-Kranenburg, and van IJzendoornm 2002). These differences might be especially apparent for individuals of different racial/ethnic backgrounds, who have been exposed to significant differences in Bronfenbrenner's nested structures. Moreover, the individuals and groups that comprise an adolescent's microsystem might interact differently across the races. For instance, White adolescents might have parents that are more involved in their school. If this is the case, then a more thorough understanding is necessary in order to ensure programming is sensitive to the differences within the environment in which these schools are located and from which the adolescents are living. While an increasing number of bullying programs exist, some programs might be more effective than others because of these differences.

Accordingly, the aim of this study is to apply the ecological model to explore whether factors related to bullying, victimization, and bullying/victimization are similar across Whites and Blacks in the U.S.

\section{Theoretical framework}

Bronfenbrenner $(1977,1979)$ proposed that individual development and behavior can be influenced by the ecological environment, which is regarded as a set of interrelated, nested structures. An individual is an inseparable part of multiple, interrelated systems that shape adolescent developmental processes, including the microsystem (relations of individuals with immediate settings), mesosystem (interrelations among the microsystems), exosystem (settings which do not directly influence the individual), and macrosystem (cultural or subcultural patterns) (Bronfenbrenner 1977, 1979). An important aspect of the ecological model is that developmental influences (e.g., peer relations) are shaped by the characteristics of the community in which the youth resides (Szapocznik and Douglas Coatsworth 1999). These influences contribute toward the racial identity development of adolescents and have consequences for their psychosocial wellbeing (Hughes et al. 2006).

For years, research has been conducted on the risk and protective factors of bullying and victimization at the systems noted above. Microsystem-level factors include occurrences and relationships in the immediate environment, such as dynamics in the home, peer groups, and school. In the home setting, research reveals that parental monitoring, parent-adolescent communications, and parental supports reduced bullying and victimization risks (Conners-Burrow et al. 2009; Elsaesser et al. 2017). Theories, from attachment theory to social learning theory, have been applied to account for how relations with parents might influence adolescents' bullying involvement (Hong et al. 2018). Attachment theorists might argue that youth with insecure attachment with their parents through lack of parental monitoring, communication, and support might be at an elevated risk of victimization because they may find it difficult connecting with their peers (Allen et al. 2007). 
With respect to peer-level factors, bullying and victimization are positively linked to deviant peer affiliation (Espelage, Holt, and Henkel 2003) but are negatively linked with supportive friendships and time spent with peers (Bollmer et al. 2005; Kendrick, Jutengren, and Stattin 2012). Deviant peer affiliation can increase adolescents' problem behaviors, which are often learned and reinforced in peer groups (Elliott and Menard 1996). Youth who regularly associate with deviant peers also have an increased risk of victimization, as they are perceived by their peers as potential targets due to low guardianships (Lauritsen, Sampson, and Laub 1991). Research also offers support for the potential protective functioning of supportive friendships and time spent with peers, such as providing a buffer against victimization (Bollmer et al. 2005).

School-level factors have been researched extensively, and protective factors in school that are found to diminish bullying risks include teacher support, teachers' involvement, and school bonding (Flaspohler et al. 2009; Wei et al. 2010). School environment is recognized as a salient influence in an adolescent's adjustment (Aspy et al. 2012), and research shows that the more exposure adolescents have to environmental assets, the less likely they are involved in violent behaviors (Aspy et al. 2012). Moreover, a positive school environment can function to enhance the adoption of and commitment to prevention program as well as to increase help-seeking behavior, which can reduce bullying risk (Bradshaw et al. 2009; Eliot et al. 2010).

In terms of mesosystem-level, although the home is the main context in which child development occurs - especially in the first five to 6 years of life before formal schooling begins, it is but one of numerous settings in which developmental process(es) can and do take place (Bronfenbrenner 1979). This system level is conceptualized as the interrelations among two or more microsystems (e.g., family and peer groups), each of which includes the individual (Bronfenbrenner 1994). Examples of mesosystems are interrelations between the adolescent's peer group or school and the home environment. For instance, parental involvement and interactions with others (e.g., teachers) can influence adolescents' behavior and interactions with peers in school (Lee and Song 2012). Involvement in violence can be reinforced through deviant peer association (Akers 1998), which may occur as a result of weak bonds, as indicated by, for example, a lack of communication and interactions in the home.

Research on exosystem- and macrosystem-level factors related to bullying and victimization is limited. This is unfortunate as psychological development of adolescents is influenced not only by direct settings (e.g., home) but also by broader level occurrences which may affect the adolescent's interactions in these settings, such as economic conditions (Bronfenbrenner 1979). Exosystem is defined as linkages and processes between two or more settings. However, only one directly affects the individual (Bronfenbrenner 1979). Macrosystem is defined as the cultural "blueprint" that may influence the social structures and activities occurring in the immediate system levels (Bronfenbrenner 1994). Examples of the macrosystem are "material resources, opportunity structures, alternatives throughout the life course, lifestyles and customs, and shared knowledge and cultural beliefs" (Eamon 2000:261). Some studies have explored macrosystem-level factors, including SES, income inequality, and poverty, and how they might elevate bullying risk in adolescents. Findings suggest that poverty and residence in communities with highincome inequality are associated with victimization (Carlson 2006; Chaux, Molano, and Podlesky 2009; Elgar et al. 2009). According to Carlson (2006), higher levels of poverty were associated with victimization. In a wider sense, adolescents in countries with high-income inequality report more bullying than those in countries with low-income inequality (Elgar et al. 2009). Poverty is related to power differentials between those with access to resources and those without access, which might lead to bullying perpetrated by those with more power over those with less power (Chaux, Molano, and Podlesky 2009).

\section{Race and bullying}

It has been reported that bullying involvement varies across race (Scherr and Larson 2010), although there is a more complex picture concerning involvement. Studies have documented that Black adolescents are involved in more perpetration, relative to adolescents of other racial groups 
(Carlyle and Steinman 2007; Wang, Iannotti, and Nansel 2009), while other studies report no racial differences (e.g., Seals and Young 2003). In addition, Blacks experience higher rates of victimization than adolescents of other races (Koo, Peguero, and Shekarkhar 2012; Rhee, Lee, and Jung 2017). Also, according to the Department of Justice, more Black students (20\%) reported being frequently teased, made fun of or called names, or socially excluded than White students (15\%) (Zhang, MusuGillette, and Oudekerk 2016). In contrast, according to Juvonen, Graham, and Schuster (2003), Whites were significantly more likely to be classified as victims than their Black, Hispanic, and Asian peers. Sawyer, Bradshaw, and O’Brennan (2008) also found that Black youth tended to be less likely than their White peers to indicate being a bullying victim.

Spriggs et al. (2007) found that parental communication, social isolation, and relations with classmates were negatively associated with bullying across racial/ethnic groups, but that living with two biological parents was a protective factor for Whites only. The study also found that two school-level factors, satisfaction, and performance, were negatively related to bullying for Whites yet were irrelevant for Blacks. In a more recent study, fathers' parental monitoring was found to be negatively related to bullying for Whites, while not significant for Blacks (Hong, Ryou, and Piquero 2017). These results offer some (albeit limited) support for the contention that there may be distinctive ways in which ecological factors operate in the lives of adolescents of different racial or ethnic groups.

\section{The present study}

The present study builds on Hong, Ryou, and Piquero (2017) study, which explored family-level factors related to bullying and victimization experiences of Blacks and Whites. More specifically, we investigate whether there are racial differences in ecological level factors associated with subtypes of bullying involvement (perpetration, victimization, bully/victim) at the microsystem, mesosystem, and macrosystem. This study contributes to the literature in several respects. First, studies have found inconsistent results with respect to differences in bullying perpetration and victimization, suggesting the need for more research on this topic. Moreover, research needs to look not only at the differences in rates but also in understanding the underlying factors. By examining factors at the microsystem, mesosystem, and macrosystem this study provides a more thorough and detailed background on the differences in variables associated with bullying involvement across race. Given the differences in exposure to risk factors that Black and White adolescents experience, there is a reason to believe that these factors may operate differently across race. Understanding these differences is critical for anti-bullying program implementation because awareness of potential differences between races in Bronfenbrenner's ecological model can help to ensure that victims, perpetrators, and bully/victims are provided with the appropriate intervention for their specific needs.

The research questions are as follows: (1) Are the microsystem, mesosystem, and macrosystem factors differentially associated with bullying for White and Black youth when controlling for sex and age? (2) Are the microsystem, mesosystem, and macrosystem factors differentially associated with victimization for both racial groups when controlling for sex and age? and (3) Are the microsystem, mesosystem, and macrosystem factors differentially associated with bullying/victimization for both racial groups when controlling for sex and age?

\section{Methods}

\section{Sample and data}

Data were derived from the 2009 to 2010 Health Behavior in School-Aged Children (HBSC) study in the U.S. The HBSC is a standardized, international World Health Organization study consisting of repeated cross-sectional surveys in the 43 participating countries. Data were collected through school-based surveys utilizing random sampling to select a proportion of adolescents, aged 11,13, and 15 years (Currie et al. 2012). The primary sampling units (districts 
comprising one or more public schools) were stratified within each Census Division. The districts were classified as urban or rural, based on a comprehensive list of schools from the Quality Education Data. The primary sampling units had at least 10 schools, and those with large enrollments were considered as separate primary sampling units. A total of 1,302 primary school units were created, and a sample of 94 primary school units were selected. Also, a list of private and Catholic schools were obtained from the Quality Education Data and were assigned based on their locations to the 1,302 primary sampling units. All private and Catholic schools were eligible for inclusion into the 94 sampled primary school units. In the second stage, schools were selected from the sampled primary school units, and 314 schools participated in the study. In the final stage, classes were selected from the schools designated for sampling students from specific grades. Respondents consisted of public, Catholic, and private school students in grades 5-10 in 50 states and the District of Columbia. In the original sampling, 475 schools were considered to be eligible. Of these schools, 161 schools did not participate, and of the 314 schools, 31 did not complete the questionnaire.

The school-based survey includes a self-reported questionnaire completed by students in the classroom and covers a range of health indicators and health-related behaviors, along with life circumstances (Roberts et al. 2009). Survey questions include information on socio-demographic factors, social background, social context, health outcomes, health behaviors, and risk behaviors (Roberts et al. 2009). The survey took approximately 45 minutes to complete and was administered in a classroom by teachers who read scripts that explained the procedure. Data for the study are from the cross-sectional 2009-2010 data set. Table 1 presents the descriptive statistics for the total sample, White sample, and Black sample.

Table 2 shows a cross-tabulation of the four bullying subgroups (uninvolved, victims-only, bullies-only, bully/victims) across the two racial groups, the results of which indicate a significant association between the two variables $\left(\chi^{2}=29.56, p<.001, \varphi_{c}=.082\right)$. As is clear from the standardized residuals reported in Table 2, the significant effect was driven by certain roles that Blacks and Whites take on. Blacks were overrepresented in the uninvolved role and underrepresented in the victim and the bully/victim roles. In contrast, Whites were overrepresented in the victim role.

Table 1. Descriptive statistics of the study variables.

\begin{tabular}{|c|c|c|c|c|c|c|c|c|c|}
\hline & \multicolumn{3}{|c|}{ Total $(N=4,466)$} & \multicolumn{3}{|c|}{ Whites $(N=3,386)$} & \multicolumn{3}{|c|}{ Blacks $(N=1,080)$} \\
\hline & $N(\%)$ & $M$ & $S D$ & $N(\%)$ & $M$ & $S D$ & $N(\%)$ & M & $S D$ \\
\hline Age & & 13.88 & 1.26 & & 13.85 & 1.24 & & 13.97 & 1.34 \\
\hline \multicolumn{10}{|l|}{ Sex } \\
\hline Male & $2,223(49.8)$ & & & $1,701(50.2)$ & & & $522(48.3)$ & & \\
\hline Female & $2,243(50.2)$ & & & $1,685(49.8)$ & & & $558(51.7)$ & & \\
\hline \multicolumn{10}{|l|}{ Parental monitoring } \\
\hline Mother's parental monitoring & & 10.97 & 1.55 & & 11.05 & 1.54 & & 10.73 & 1.59 \\
\hline Father's parental monitoring & & 9.39 & 2.77 & & 9.79 & 2.51 & & 8.13 & 3.14 \\
\hline Parent-child communication & & 7.13 & 2.00 & & 7.25 & 1.93 & & 6.74 & 2.16 \\
\hline Elder brother/sister communication & & 4.58 & 2.49 & & 4.32 & 2.35 & & 5.37 & 2.75 \\
\hline Parental support & & 10.16 & 1.79 & & 10.22 & 1.76 & & 9.95 & 1.86 \\
\hline Parental treatment & & 4.06 & 1.15 & & 4.09 & 1.13 & & 3.97 & 1.24 \\
\hline Number of friends & & 7.07 & 1.32 & & 7.05 & 1.31 & & 7.10 & 1.35 \\
\hline Time spent with friends/peers & & 10.29 & 5.11 & & 10.08 & 5.03 & & 10.95 & 5.31 \\
\hline Delinquent friend influences & & 8.13 & 3.99 & & 8.10 & 3.90 & & 8.24 & 4.26 \\
\hline Positive peer relations in school & & 10.95 & 2.49 & & 10.92 & 2.44 & & 11.02 & 2.62 \\
\hline Family socioeconomic status & & 3.43 & 0.91 & & 3.45 & .89 & & 3.38 & .96 \\
\hline Bullying victimization & & 13.92 & 5.62 & & 13.87 & 5.35 & & 14.07 & 6.37 \\
\hline Bullying perpetration & & 12.66 & 4.60 & & 12.50 & 4.28 & & 13.17 & 5.44 \\
\hline \multicolumn{10}{|l|}{ Bully-victim } \\
\hline Uninvolved & $2,509(56.2)$ & & & $1,845(54.5)$ & & & $664(61.5)$ & & \\
\hline Victim only & $632(14.2)$ & & & $524(15.5)$ & & & $108(10.0)$ & & \\
\hline Bullying only & $773(17.3)$ & & & $572(16.9)$ & & & 201(18.6) & & \\
\hline Bully/victim & $552(12.4)$ & & & $445(13.1)$ & & & $107(9.9)$ & & \\
\hline
\end{tabular}


Table 2. Cross-tabulation for race by bully subgroups, showing $n$, row-percentages, and standardized residuals.

\begin{tabular}{|c|c|c|c|c|c|c|c|c|c|}
\hline & & & \multicolumn{4}{|c|}{ Bully Subgroups } & \multirow[b]{2}{*}{ Total } & \multirow[b]{2}{*}{$x^{2}$} & \multirow[b]{2}{*}{$\varphi_{c}$} \\
\hline & & & Uninvolved & Victims-only & Bullies-only & Bully/victims & & & \\
\hline \multirow[t]{8}{*}{ Race } & Black adolescents & $n$ & 664 & 108 & 201 & 107 & 1,080 & $29.56 a$ & $.082 a$ \\
\hline & & $\%$ & $60.8 \%$ & $10.2 \%$ & $19.0 \%$ & $10.1 \%$ & $100.0 \%$ & & \\
\hline & & $z$ & 2.1 & -3.5 & 1.2 & -2.1 & & & \\
\hline & White adolescents & $n$ & 1,845 & 524 & 572 & 445 & 3,386 & & \\
\hline & & $\%$ & $54.5 \%$ & $15.5 \%$ & $16.9 \%$ & $13.1 \%$ & $100.0 \%$ & & \\
\hline & & $z$ & -1.2 & 1.9 & -0.7 & 1.2 & & & \\
\hline & Total & $N$ & 2,509 & 632 & 773 & 552 & 4,466 & & \\
\hline & & $\%$ & $56.2 \%$ & $14.2 \%$ & $17.3 \%$ & $12.4 \%$ & $100.0 \%$ & & \\
\hline
\end{tabular}

${ }^{a} p<.001$.

\section{Measures}

Perpetration was measured with the question, "How often have you bullied another student(s) at school in the past couple of months in the way listed below" with eleven subcategories including:

(a) "I called another student(s) mean names, and made fun of, or teased him or her in a hurtful way; (b) "I kept another student(s) out of things on purpose, excluded him or her from my group of friends, or completely ignored him or her"; (c) "I hit, kicked, pushed, shoved around, or locked another student(s) indoors"; (d) "I spread false rumors about another student(s) and tried to make others dislike him or her"; (e) "I bullied another student(s) with mean names and comments about his or her race or color"; (f) "I bullied another student(s) with mean names and comments about his or her religion"; (g) "I made sexual jokes, comments, or gestures to another student(s)"; (h) "I bullied another student(s) using a computer or e-mail messages or pictures"; (i) "I bullied another student(s) using a cell phone"; (j) "I bullied others outside of school using a computer or email messages or pictures"; and (k) "I bullied others outside of school using a cell phone".

Response options are $0=\mathrm{I}$ have not bullied another student in this way in the past couple of months, $1=\mathrm{It}$ has only happened once or twice, $2=2$ or 3 times a month, $3=$ about once a week, and $4=$ several times a week. The final perpetration measure is the sum of the eleven items $(\alpha=.92)$.

Victimization was measured with the following question, "How often got bullied" with eleven subcategories that are identical to the perpetration items noted above but were re-worded to reflect victimization (e.g., "I was called names, was made fun of, or teased in a hurtful way.") $(\alpha=.88)$. Response options are also identical to perpetration but reworded to reflect victimization.

Bully/victim was measured using two items, "How often got bullied" and "How often have you bullied another student(s) at school in the past couple of months". Response options are $0=$ I haven't been bullied/ haven't bullied another student at school the past couple of months, $1=$ only once or twice, $2=2$ or 3 times a month, $3=$ about once a week, and $4=$ several times a week. All responses were dichotomized as $0=$ I haven't been bullied/haven't bullied and $1=\mathrm{I}$ have been bullied/bullied more than once, and then combined. These dichotomized responses were classified into four clusters: $1=$ uninvolved, $2=$ victimonly, 3 = bully-only, and 4 = bully/victim.

Microsystem variables included family-level factors. Parental monitoring was measured with the questions, "How much does your mother (or female guardian) really know about ... ?" and "How much does your father (or male guardian) really know about ... ?" with the following subcategories, "Who your friends are", "Where you are after school", and "Where you go at night". Response options initially were: $1=\mathrm{s} / \mathrm{he}$ knows a lot, 2 =s/he knows a little, 3 = s/he doesn't know anything, and $4=$ don't have/see mother/father/ guardian and were reverse coded. They were summed for each item. Parental monitoring was divided into "by mother" ( $\alpha=.75)$ and "by father" ( $\alpha=.91$ ), and the variables were summed, respectively, to either mother or father subscales. Parent-child communication was measured with the same question asked twice (once for "mother" and once for "father"): "How easy is it for you to talk to the following persons about things that really bother you?" The response options initially were: 1 = very easy, 2 = easy, 3 = difficult, $4=$ very difficult, and $5=$ don't have or see this person; they were reverse coded. The two items were summed. Elder brother/sister communication was also measured with the same question asked twice: "How is it for you to talk to the following persons about things that really bother you?" This question was asked for "Elder (1) 
brother(s)" and "Elder sister(s)". Response options initially were $1=$ very easy, 2 = easy, $3=$ difficult, 4 = very difficult, and $5=$ don't have or see this person. They were reverse coded and were summed for the two items. Parental support was measured with the statement, "My parents/guardian" with the following subcategories, "helps me as much as I need", "understands my problems and worries", and "makes me feel better when I am upset" $(\alpha=.80)$. Response options initially were $1=$ almost always to $4=$ don't have or don't see parents/guardians; they were reverse coded. Parental treatment consists of one question, "Have your parent(s) treated you fairly?" with response options, $1=$ never to $5=$ always.

Also included are peer-level factors. Number of friends was measured with the question, "At present, how many close male and female friends do you have?" with the response option for males and females, $1=$ none to $4=$ three or more. Time spent with friends/peers was measured with three questions, "How many days per week do you usually spend time with friends right after school?", "How many evenings per week do you usually spend out with your friends", and "How often do you talk to your friend(s) on the phone or send them text messages or have contacts through the internet?" $(\alpha=.64)$. Response options for the first question range from 0 days to 6 days, from 0 evenings to 7 evenings for the second question, and $1=$ rarely or never to $5=$ every day for the last question. Since the three questions have different response options, linear transformation was applied for the response options of the first and last questions in order to convert them to a common metric. The range of the response for the three items therefore was adjusted from 0 to 7. Delinquent friend influences were measured with the question, "How many of your friends would you estimate ..." with the following subcategories: (a) smoke cigarettes, (b) drink alcohol, (c) get drunk at least once a week, (d) smoke/use marijuana, and (e) carry a weapon $(\alpha=.88)$. Response options range from $1=$ none to $5=$ all. Positive peer relations in school was measured with the following three statements $(\alpha=.74)$ : “The student in my class(es) enjoy being together", "Most of the students in my class(es) are kind and helpful", and "Other students accept me as I am". Response options were 1 = strongly agree to 5 = strongly disagree but were reverse coded so that higher scores reflect more positive peer relations.

Mesosystem variables included delinquent friend influences $\times$ parent-child communication and delinquent friend influence $\times$ elder brother/sister communication, which were generated using meancentred versions of the relevant variables (Aiken, West, and Reno 1991).

The macrosystem variable, family SES, was measured with the question, "How well off do you think your family is?" Response options were $1=$ very well off to $5=$ not at all well off but were reverse coded so that a higher score reflects higher family SES.

Covariates as originally measured in the study include age ("How old are you?"; $1=10$ or younger, $2=11,3=12,4=13,5=14,6=15,7=17$, and $8=17$ or older) and $\operatorname{sex}$ ("Are you a boy or a girl?"; 0 = boy and 1 = girl).

\section{Analyses}

Analyses included bivariate correlations, hierarchical multivariate regressions, and multinomial regressions separately for the White $(N=3,386)$ and Black $(N=1,080)$ samples. Multivariate regressions for victimization and perpetration were estimated using Ordinary Least Squares regression. To compare racial differences, coefficient comparisons were conducted using Paternoster et al.'s (1998) formula. To ease the interpretation of the results regarding bully-victims, results of multinomial logistic regression were converted into Relative Risk Ratios (RRR). All interaction terms were based on Aiken, West, and Reno (1991) analysis and interpretation methods of interaction effects in multiple regression. Simple slope analysis was used to interpret the interaction effect. Multinomial regressions were used to examine racial differences in adolescents' status as a bully, victim, or bully/victim (compared to uninvolved status). Analyses were conducted using SPSS 18.0 and STATA 12 software. ${ }^{1}$

${ }^{1}$ None of the correlations exceeded $r=0.51$, which limits potential problems associated with collinearity in the model space. 


\section{Results}

Tables 3 and 4 display the results of hierarchical multivariate regression for Whites and Blacks for victimization and perpetration, respectively.

\section{Hierarchical multivariate regression results}

In terms of victimization for Whites (see Table 3$)$, we found that mother's parental monitoring $(B=-.13$, $p<.05)$, parental support $(B=-.16, p<.05)$, parental treatment $(B=-.46, p<.001)$, and positive peer relations in school $(B=-.56, p<.001)$ were negatively related to victimization. On the other hand, parent-child communication $(B=.13, p<.05)$, elder brother/sister communication $(B=.09, p<.05)$, and delinquent friend influences $(B=.13, p<.001)$ were positively associated with victimization. The interaction terms were not significant, nor did they alter the significance of the coefficient estimates reported above.

With respect to victimization for the Black adolescent sample (see Table 3, Model B1), mother's parental monitoring $(B=-.41, p<.001)$, parental treatment $(B=-.70, p<.001)$, number of friends $(B=-.36, p<.05)$, and positive peer relations in school $(B=-.40, p<.001)$ were negatively and significantly related to victimization in anticipated ways. Regarding the interaction terms, although the main effects of delinquent friend influences and parent-child communication on victimization were not significant, the interaction between delinquent friend influences $\times$ parent-child communication $(B=-.06, p<.01)$ was negatively associated with victimization. ${ }^{2}$

Figure 1 displays the results of simple slope analysis for this particular interaction term for Blacks. As can be seen, the effect of high delinquent friends on victimization is diminished when parentchild communication is high. Conversely, when parent-child communication is low and delinquent friend influences are at their highest point, victimization is at its highest point.

Regarding perpetration for Whites (see Table 4$)$, mother's parental monitoring $(B=-.27, p<.001)$ and positive peer relations in school $(B=-.16, p<.001)$ were negatively and significantly associated with perpetration. Time spent with friends/peers $(B=.08, p<.001)$ and delinquent friend influences $(B=.26$, $p<.001)$ exerted positive effects on perpetration. The main effects of parent-child communication and elder brother/sister communication were not significantly associated with perpetration, but interaction terms were found to be positive and significantly related to perpetration: delinquent friend influences $x$ parent-child communication $(B=.02, p<.05)$ and delinquent friend influences $\times$ elder brother/sister communication $(B=.03, p<.001)$. As shown in Figure 2 , when high delinquent peer influences are coupled with higher parent-child communication (easier in communication), perpetration risk is higher than when the corresponding variables are their low points. The same is observed for elder brother/sister communication and delinquent friend influences.

For perpetration for Blacks, we found that parent-child communication $(B=.20, p<.05)$, time spent with friends/peers $(B=.10, p<.01)$, and delinquent friend influences $(B=.18, p<.001)$ were positively associated with perpetration (see Table 4$)$. Parental treatment $(B=-.48, p<.01)$, number of friends $(B=-.27, p<.05)$, and positive peer relations in school $(B=-.26, p<.001)$ were negatively related to perpetration. Regarding the interaction terms (Model B2), delinquent friend influences $\times$ parent-child communication $(B=-.06, p<.001)$ was negatively associated with perpetration. ${ }^{3}$ This is contrary to the

\footnotetext{
${ }^{2}$ For the coefficient comparison tests across race, the corresponding $Z$ statistics (Z-test) were calculated revealing mother's parental monitoring $(Z=1.99, p<.05)$ and delinquent friend influences $\times$ parent-child communication $(Z=3.37, p<.001)$ were significant. This indicates that the effects of mother's parental monitoring and delinquent friend influences $\times$ parent-child communication were significantly different between Whites and Blacks. Apart from the significant variables, the results of the corresponding Z-test indicate few differences between the two samples with respect to how the covariates relate to victimization.

${ }^{3}$ Regarding the coefficient comparison tests on perpetration for Whites and Blacks, parental treatment $(z=2.12, p<.05)$, number of friends $(z=2.52, p<.05)$, delinquent friend influences $\times$ parent-child communication $(z=4.00, p<.001)$, and delinquent friend influences $\times$ elder brother/sister communication $(z=2.17, p<.05)$ were found to be significant, indicating that the coefficient estimates for these variables are significantly different from one another across race.
} 


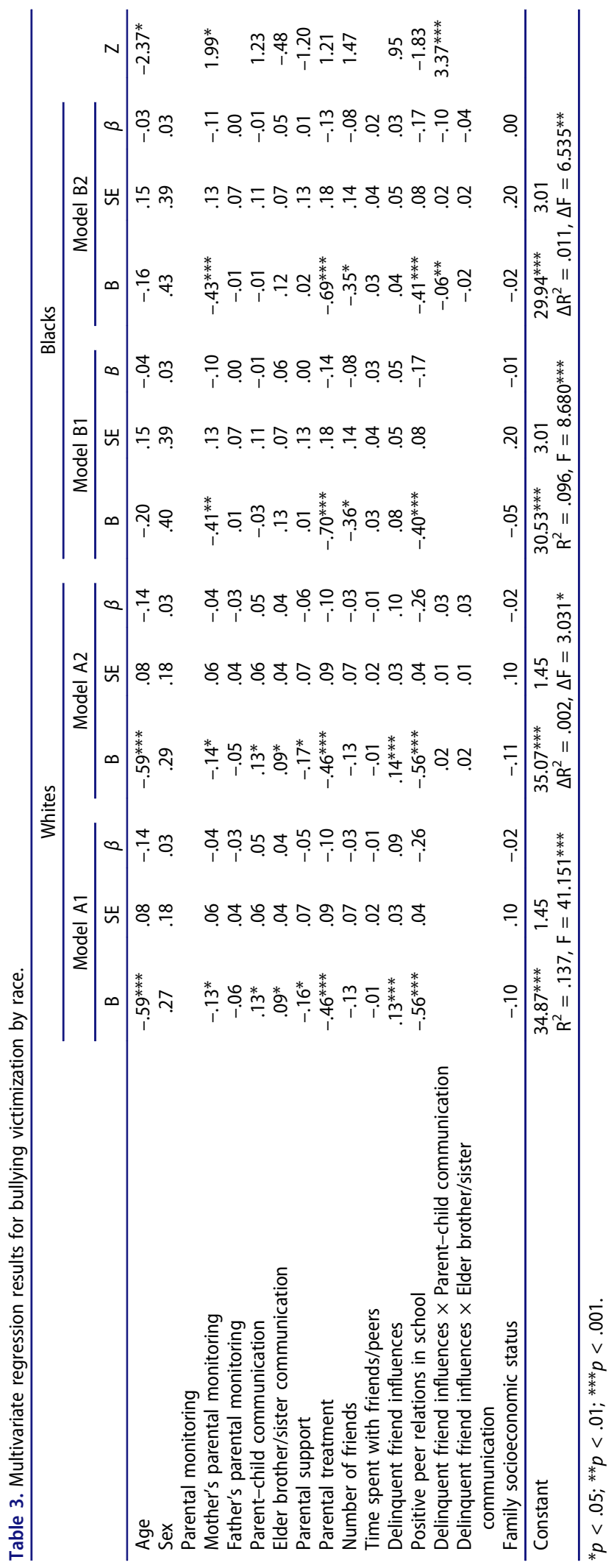




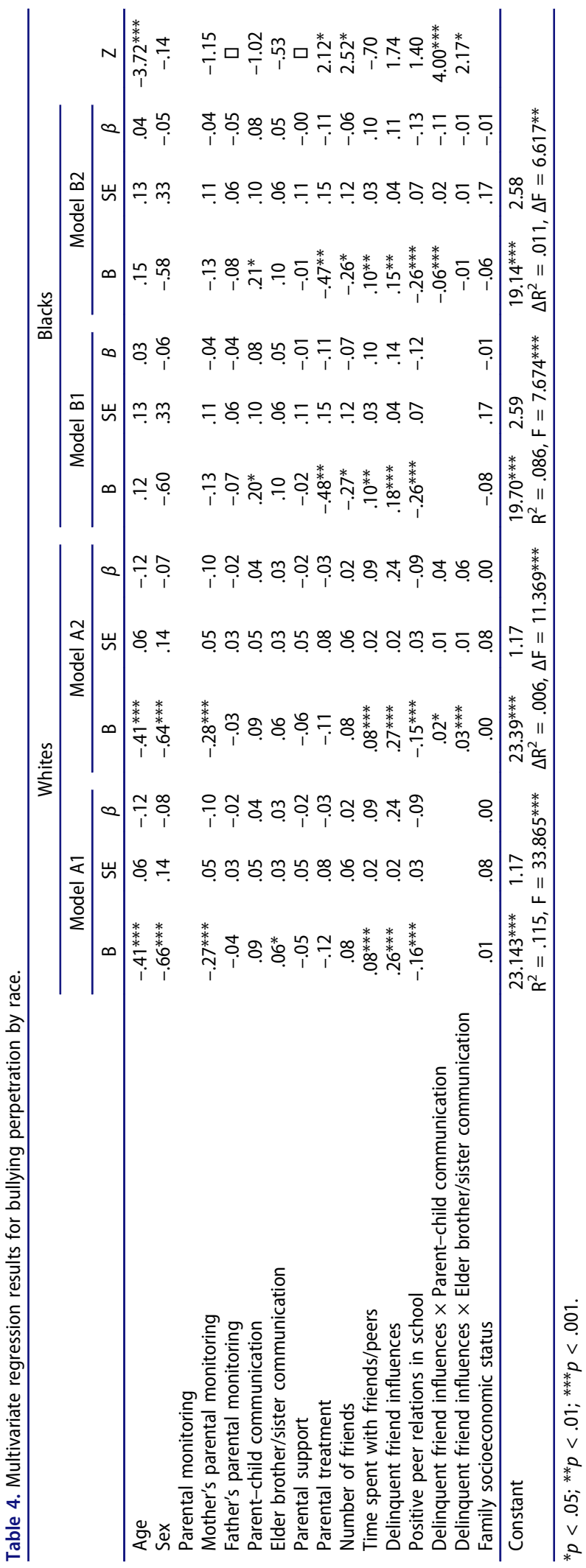




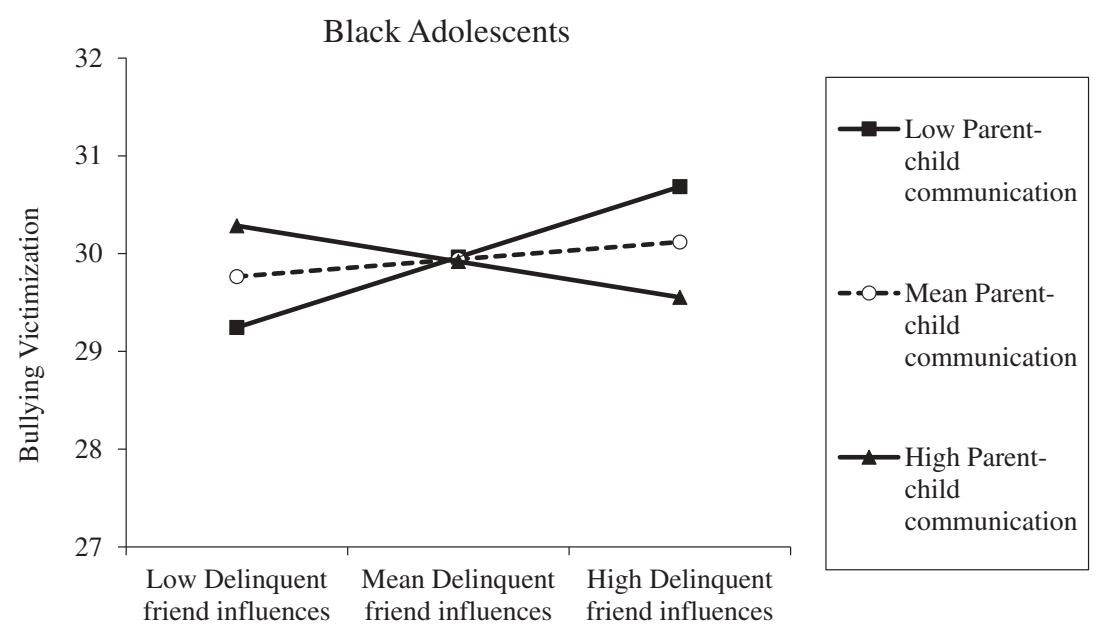

Figure 1. Simple slope for delinquent friend influences $\times$ Parent-child communication on bullying victimization for Black adolescents.
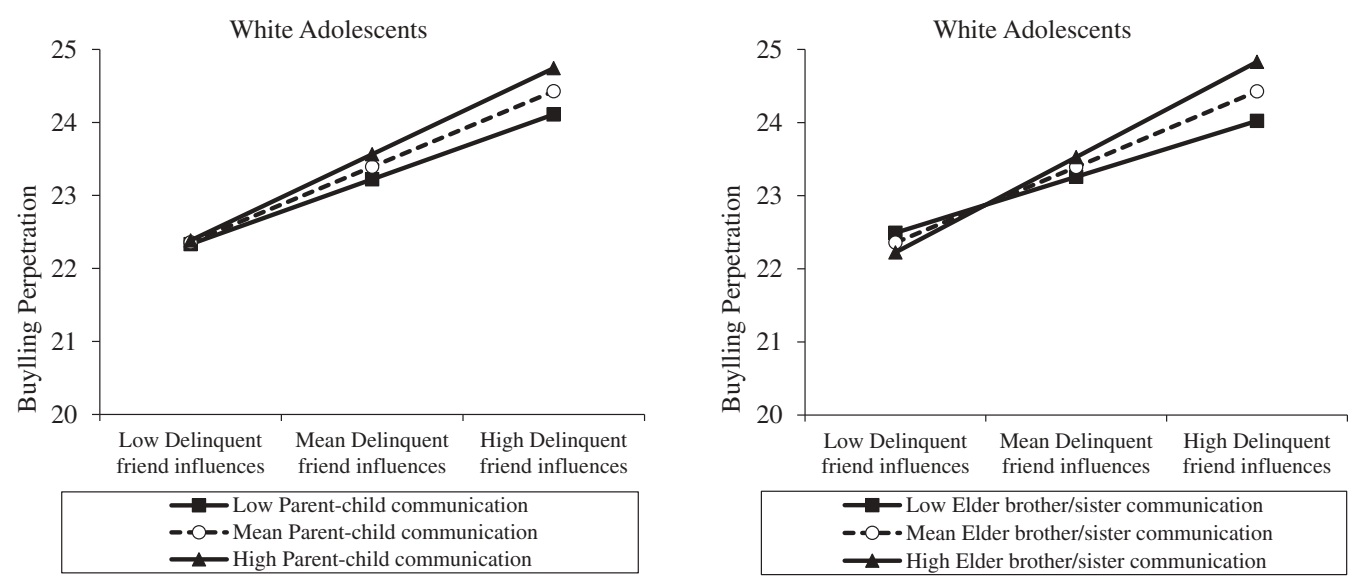

Figure 2. Simple slope for interactions on bullying perpetration for White adolescents.

results for Whites where delinquent friend influences $\times$ parent-child communication was positively related to perpetration. Figure 3 presents the results of simple slope analysis for the significant interaction term for Blacks. When adolescents have a high level of parent-child communication, bullying occurs at a similar level whether the delinquent friend influence is high or low. However, the likelihood of bullying is highest when low parent-child communication is met with high delinquent friend influences.

\section{Multinomial regressions for bully-victim status for whites}

Table 5 displays the multinomial logistic regression results distinguishing across bully-victim status for Whites (The reference group is the uninvolved group.) Comparing victim-only and uninvolved groups, parental treatment $(R R R=.79, p<.001)$ and positive peer relations in school $(R R R=.79, p<.001)$ were found to be significantly different between the two groups. These findings indicate that a one-unit increase in (good) parental treatment or positive peer relations is negatively related to victimization, 


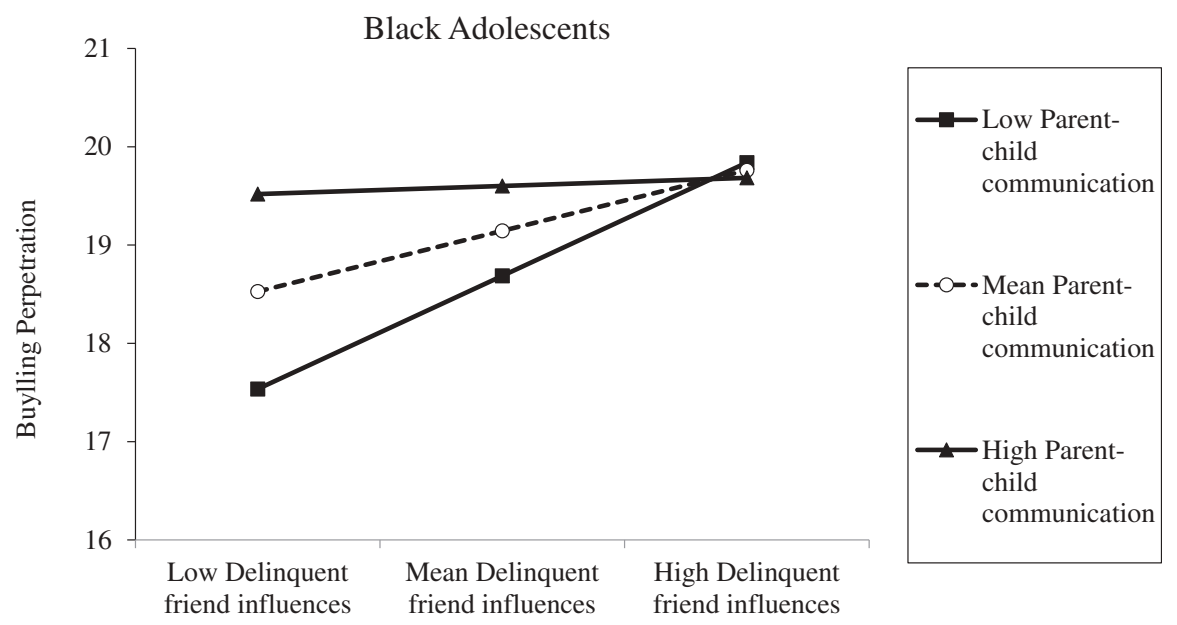

Figure 3. Simple slope for delinquent friend influences $\times$ Parent-child communication on bullying perpetration for Black adolescents.

Table 5. Multinomial logistic regression results for Whites.

\begin{tabular}{|c|c|c|c|c|c|c|c|c|c|c|c|c|}
\hline \multirow[b]{3}{*}{ Age } & \multicolumn{4}{|c|}{$\begin{array}{l}\text { Victim-only } \\
\text { vs. Uninvolved }\end{array}$} & \multicolumn{4}{|c|}{$\begin{array}{l}\text { Bullies-only } \\
\text { vs. Uninvolved }\end{array}$} & \multicolumn{4}{|c|}{$\begin{array}{l}\text { Bully-Victim } \\
\text { vs. Uninvolved }\end{array}$} \\
\hline & \multirow{2}{*}{$\begin{array}{l}\text { RRR } \\
.75^{* * * *}\end{array}$} & \multirow{2}{*}{$\begin{array}{l}\text { SE } \\
.03\end{array}$} & \multicolumn{2}{|c|}{$95 \% \mathrm{Cl}$} & \multirow{2}{*}{$\begin{array}{l}\text { RRR } \\
.89^{*}\end{array}$} & \multirow{2}{*}{$\begin{array}{l}\text { SE } \\
.04\end{array}$} & \multicolumn{2}{|c|}{$95 \% \mathrm{Cl}$} & \multirow{2}{*}{$\frac{\text { RRR }}{.69^{* * *}}$} & \multirow{2}{*}{$\begin{array}{l}\text { SE } \\
.03\end{array}$} & \multicolumn{2}{|c|}{$95 \% \mathrm{Cl}$} \\
\hline & & & .68 & .82 & & & .82 & .97 & & & .63 & .76 \\
\hline Sex & .88 & .09 & .71 & 1.08 & $.54^{* * *}$ & .06 & .44 & .66 & $.68^{* *}$ & .08 & .54 & .85 \\
\hline Parental monitoring & & & & & & & & & & & & \\
\hline Mother's parental monitoring & .95 & .04 & .88 & 1.03 & $.91^{* *}$ & .03 & .85 & .97 & .96 & .04 & .88 & 1.03 \\
\hline Father's parental monitoring & 1.00 & .02 & .96 & 1.05 & 1.01 & .02 & .96 & 1.05 & 1.02 & .03 & .97 & 1.07 \\
\hline Parent-child communication & 1.00 & .03 & .94 & 1.07 & .98 & .03 & .92 & 1.05 & .98 & .04 & .92 & 1.06 \\
\hline Elder brother/sister communication & .97 & .02 & .93 & 1.01 & 1.01 & .02 & .97 & 1.06 & 1.02 & .02 & .97 & 1.07 \\
\hline Parental support & 1.03 & .04 & .96 & 1.12 & .98 & .04 & .91 & 1.06 & $.91^{*}$ & .04 & .84 & .98 \\
\hline Parental treatment & $.79^{* * *}$ & .04 & .71 & .88 & .92 & .05 & .83 & 1.02 & $.89^{*}$ & .05 & .79 & .99 \\
\hline Number of friends & .96 & .04 & .89 & 1.03 & $1.12^{*}$ & .05 & 1.02 & 1.22 & 1.03 & .05 & .95 & 1.13 \\
\hline Time spent with friends/peers & .98 & .01 & .96 & 1.00 & $1.06^{* * *}$ & .01 & 1.04 & 1.08 & 1.01 & .01 & .99 & 1.04 \\
\hline Delinquent friend influences & 1.02 & .02 & .98 & 1.05 & $1.14^{* * *}$ & .02 & 1.11 & 1.17 & $1.12^{* * *}$ & .02 & 1.09 & 1.16 \\
\hline Positive peer relations in school & $.79^{* * *}$ & .02 & .76 & .83 & $.89 * * *$ & .02 & .85 & .93 & $.79^{* * *}$ & .02 & .76 & .83 \\
\hline $\begin{array}{l}\text { Delinquent friend influences } \\
\times \text { Parent-child communication }\end{array}$ & 1.01 & .01 & .99 & 1.02 & 1.00 & .01 & .99 & 1.02 & 1.01 & .01 & 1.00 & 1.03 \\
\hline $\begin{array}{l}\text { Delinquent friend influences } \\
\times \text { Elder brother/sister communication }\end{array}$ & 1.01 & .01 & 1.00 & 1.02 & 1.00 & .01 & .99 & 1.01 & 1.01 & .01 & 1.00 & 1.02 \\
\hline Family socioeconomic status & $\begin{array}{l}.95 \\
\mathrm{od}=\end{array}$ & .06 & .84 & 1.08 & $\begin{array}{l}.96 \\
675.5\end{array}$ & .06 & .85 & $\begin{array}{l}1.07 \\
000\end{array}$ & .96 & .06 & .84 & 1.09 \\
\hline
\end{tabular}

${ }^{*} p<.05 ;{ }^{* *} p<.01 ;{ }^{* * *} p<.001$.

meaning that such adolescents are less likely to be in the victim-only group and more likely to be in the uninvolved group.

For the comparison between bullies-only and uninvolved groups, mother's parental monitoring $(R R R=.91, p<.01)$, number of friends $(R R R=1.12, p<.05)$, time spent with friends/peers $(R R R=1.06, p<.001)$, delinquent friend influences $(R R R=1.14, p<.001)$, and positive peer relations in school $(R R R=.89, p<.001)$ were significant. Youth who reported higher mother's parental monitoring or positive peer relations in school are less likely to be in the bullies-only group and more likely to be in the uninvolved group, whereas adolescents scoring higher on number of friends, time spent with friends/peers, and delinquent friend influences are more likely to be in the bullies-only group as opposed to the uninvolved group. 
In the third comparison of bully/victim to the uninvolved group, parental support $(R R R=.91, p<.05)$, parental treatment $(R R R=.89, p<.05)$, delinquent friend influences $(R R R=1.12, p<.001)$, and positive peer relations in school $(R R R=.79, p<.001)$ were significant discriminators between the bully/victim and uninvolved groups. A higher level of parental support, parental treatment, and positive peer relations in school were each associated with a lower likelihood of membership in the bully-victim group compared to the uninvolved group, whereas a higher level of delinquent friend influences was associated with an increased risk of being in the bully-victim group compared to the uninvolved group.

Across all three comparisons, older youth and girls were more likely to be in the uninvolved 365 group compared to the other three groups.

\section{Multinomial regressions for bully-victim status for blacks}

Table 6 presents the results of multinomial logistic regression for Blacks. Comparing the victim-only and uninvolved groups, we found that parental treatment $(R R R=.82, p<.05)$, positive peer relations in school $(R R R=.89, p<.01)$, and delinquent friend influences $\times$ parent-child communication $(R R R=.97$, $p<.05)$ were significantly different between the two groups. Youth who scored higher on parental treatment or positive peer relations in school were less likely to be in the victim-only group and more likely to be in the uninvolved group. According to the simple slope analysis, which included the interaction between delinquent friend influences $\times$ parent-child communication (see Figure 4), the finding suggests that high parent-child communication (easier communication) is able to lessen the influence of high delinquent friend influences on the likelihood of victimization (compared to uninvolved). Conversely, when parent-child communication is low (difficult communication), the slope for the likelihood of being in the victim-only group increases slightly with the more delinquent friend influences the respondent reports.

In the second comparison between the bullies-only and uninvolved groups, time spent with friends/peers $(R R R=1.05, p<.01)$ and delinquent friend influences $(R R R=1.07, p<.01)$ were significant. This indicates that increases in both time spent with friends/peers and delinquent friend influences heighten the likelihood of being in the bullies-only group compared to the uninvolved group. Regarding the comparison between the bully-victim and uninvolved groups, mother's parental monitoring $(R R R=.87, p<.05)$, delinquent friend influences $(R R R=1.07, p<.05)$, and

Table 6. Multinomial logistic regression results for Blacks.

\begin{tabular}{|c|c|c|c|c|c|c|c|c|c|c|c|c|}
\hline \multirow[b]{3}{*}{ Age } & \multicolumn{4}{|c|}{$\begin{array}{l}\text { Victims-only } \\
\text { vs. Uninvolved }\end{array}$} & \multicolumn{4}{|c|}{$\begin{array}{l}\text { Bullies-only } \\
\text { vs. Uninvolved }\end{array}$} & \multicolumn{4}{|c|}{$\begin{array}{l}\text { Bully-Victim } \\
\text { vs. Uninvolved }\end{array}$} \\
\hline & \multirow{2}{*}{$\begin{array}{l}\text { RRR } \\
.94\end{array}$} & \multirow{2}{*}{$\begin{array}{l}\text { SE } \\
.08\end{array}$} & \multicolumn{2}{|c|}{$95 \% \mathrm{Cl}$} & \multirow{2}{*}{$\begin{array}{l}\text { RRR } \\
.90\end{array}$} & \multirow{2}{*}{$\begin{array}{l}\text { SE } \\
.06\end{array}$} & \multicolumn{2}{|c|}{$95 \% \mathrm{Cl}$} & \multirow{2}{*}{$\begin{array}{l}\text { RRR } \\
.83^{*}\end{array}$} & \multirow{2}{*}{$\begin{array}{l}\text { SE } \\
.07\end{array}$} & \multicolumn{2}{|c|}{$95 \% \mathrm{Cl}$} \\
\hline & & & .79 & 1.11 & & & .79 & 1.03 & & & .70 & .98 \\
\hline Sex & $1.83^{* *}$ & .42 & 1.16 & 2.87 & 1.35 & .23 & .96 & 1.89 & .83 & .18 & .53 & 1.28 \\
\hline \multicolumn{13}{|l|}{ Parental monitoring } \\
\hline Mother's parental monitoring & 1.02 & .08 & .88 & 1.19 & .95 & .05 & .85 & 1.06 & $.87^{*}$ & .06 & .76 & .98 \\
\hline Father's parental monitoring & 1.01 & .04 & .93 & 1.09 & .97 & .03 & .91 & 1.03 & 1.04 & .04 & .96 & 1.12 \\
\hline Parent-child communication & .96 & .06 & .83 & 1.07 & 1.03 & .05 & .94 & 1.14 & 1.04 & .07 & .91 & 1.18 \\
\hline Elder brother/sister communication & .97 & .04 & .89 & 1.05 & .97 & .03 & .91 & 1.04 & .98 & .04 & .90 & 1.06 \\
\hline Parental support & 1.00 & .07 & .87 & 1.15 & .96 & .05 & .86 & 1.07 & .95 & .07 & .83 & 1.10 \\
\hline Parental treatment & $.82^{*}$ & .08 & .68 & .99 & .94 & .07 & .81 & 1.10 & .89 & .09 & .73 & 1.08 \\
\hline Number of friends & 1.02 & .08 & .87 & 1.20 & 1.08 & .07 & .95 & 1.24 & 1.06 & .09 & .90 & 1.24 \\
\hline Time spent with friends/peers & 1.00 & .02 & .96 & 1.04 & $1.05^{* *}$ & .02 & 1.02 & 1.09 & .98 & .02 & .94 & 1.02 \\
\hline Delinquent friend influences & .99 & .03 & .93 & 1.06 & $1.07^{* * *}$ & .02 & 1.03 & 1.12 & $1.07^{*}$ & .03 & 1.02 & 1.13 \\
\hline Positive peer relations in school & $.89^{* *}$ & .04 & .82 & .97 & .94 & .03 & .88 & 1.01 & $.83^{* * *}$ & .03 & .77 & .90 \\
\hline $\begin{array}{l}\text { Delinquent friend influences } \times \text { Parent-child } \\
\text { communication }\end{array}$ & $.97^{*}$ & .01 & .95 & .99 & 1.00 & .01 & .98 & 1.02 & .99 & .01 & .97 & 1.02 \\
\hline $\begin{array}{l}\text { Delinquent friend influences } \times \text { Elder brother/sister } \\
\text { communication }\end{array}$ & 1.00 & .01 & .98 & 1.02 & 1.01 & .01 & .99 & 1.02 & 1.01 & .01 & .99 & 1.03 \\
\hline Family socioeconomic status & 1.17 & .14 & .93 & 1.47 & .99 & .09 & .83 & 1.18 & 1.03 & .12 & .81 & 1.29 \\
\hline \multicolumn{13}{|c|}{ Log likelihood $=-1094.811, \operatorname{LR} x^{2}(63)=124.39$, Prob $>x^{2}=.000$} \\
\hline
\end{tabular}

${ }^{*} p<.05 ;{ }^{* *} p<.01 ;{ }^{* * *} p<.001$. 


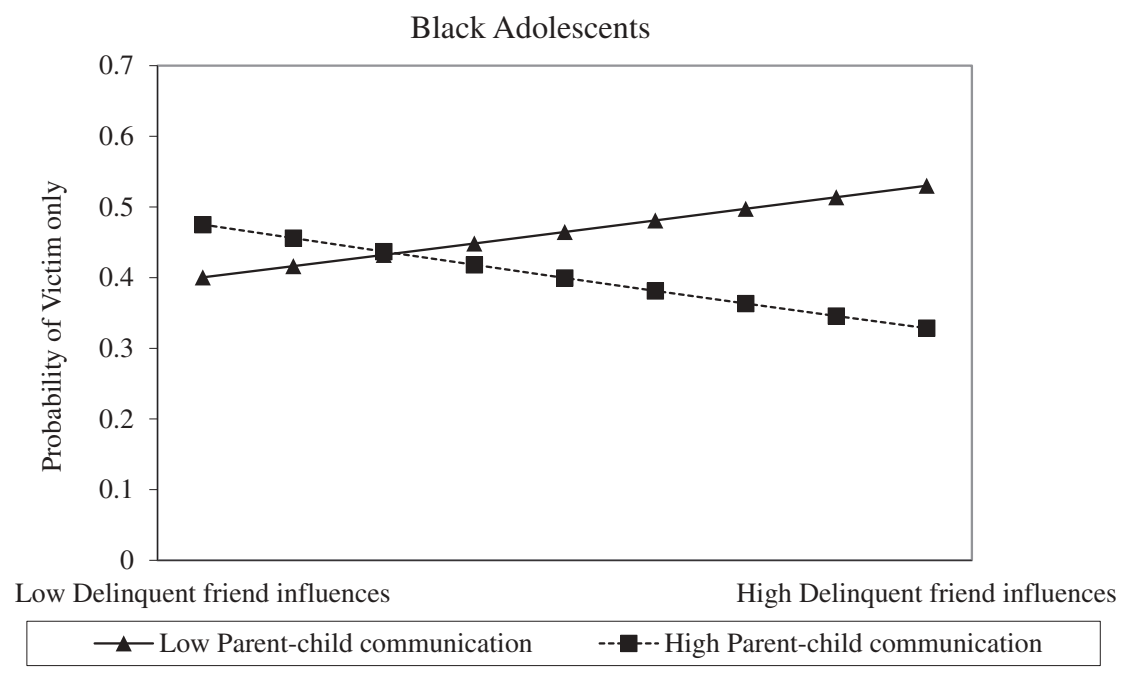

Figure 4. Simple slope for delinquent friend influences $\times$ Parent-child communication on victim only (vs. uninvolved) for Black adolescents.

positive peer relations in school $(R R R=.83, p<.001)$ were all significant, distinguishing the two groups. Youth scoring higher on mother's parental monitoring or positive peer relations in school are less likely to be bully-victim, whereas those scoring higher on delinquent friend influences are more likely than the uninvolved group to be bully-victims.

\section{Discussion}

The National Academy of Sciences, Engineering, and Medicine (2016) report on bullying identified it as a 'serious public health problem', one that could have dramatic adverse effects on the well-being and positive life-course development of children and adolescents. As a result, it is imperative that social scientists undertake rigorous empirical research aimed at understanding the correlates of bullying, victimization, and the concordance of the two in an effort not only to build the knowledge base but perhaps more importantly help inform the development of prevention and intervention efforts aimed at thwarting all types of bullying behavior. While research on bullying has had a long history, much less attention has been focused on examining racial differences with respect to how key theoretical correlates informed by Bronfenbrenner's ecological model influence various types of bullying.

Using a nationally representative sample of adolescents in the U.S., this study extended the previous work of Hong, Ryou, and Piquero (2017) by examining how several theoretically informed variables conceptualized at different levels in the ecological model were associated with both victimization and perpetration across race. Our results pointed toward some important differences between Blacks and Whites within the context of different contributions from family and peer microsystems. Particularly novel were our results relating to interactions between microsystems which revealed important ways in which family and peer experiences operate together rather than in isolation, and their signs indicated that they operated differently across Blacks and Whites. Finally, we have reported effects which are unique to those youth who are both victimized and are perpetrators of bullying behavior. Given the uniquely negative set of outcomes associated with being both a bully and a victim, such effects are important to document and to help aid prevention and intervention efforts more specifically.

Concerning victimization, our results indicate that both family and peer influences are important, but that more indices of family interaction were associated with victimization among Whites than Blacks. Specifically, among Whites, better parent-child communication and elder sibling 
communication were both associated with more victimization, while better parental support was associated with less victimization. Previous research has reported that family-level interactions serve a protective role with regards to victimization (Conners-Burrow et al. 2009; Hong, Ryou, and Piquero 2017) but our results, though based on cross-sectional data, suggest this is only true for specific forms of family interaction, and that this differs according to an adolescent's race. While the benefits of parent support are self-evident, it is less clear why White youth who feel they can easily communicate with their parents and/or siblings should be victimized more than their peers who report less easy communication. One possibility is that talking with parents is an emotionfocused coping strategy, which does not help to stop bullying which is taking place, while parental support (which includes the item, "Helps me as much as I need") provides more solution-focused discussions to take place (Tenenbaum et al. 2011).

Regardless of race, better parental treatment was associated with lower levels of victimization, which may be explained by attachment theory. Attachment theory emphasizes the importance of emotional bond between the child and parent. Youth who do not develop a secure emotional base at home may experience bullying as they may be unable to relate more positively with others (Kennedy and Kennedy 2004). Parental monitoring is associated with lower levels of victimization (Elsaesser et al. 2017; Hong, Ryou, and Piquero 2017) and may protect against negative sequelae (Jantzer et al. 2015). Youth who are consistently monitored by parents may be less inclined to be involved in bullying as they are more likely to be supervised (Spriggs et al. 2007). However, higher maternal monitoring was also found to be associated with lower levels of victimization, significantly more so for Blacks than Whites. This finding was somewhat contrary to Hong, Ryou, and Piquero (2017), who reported that maternal monitoring was negatively correlated with victimization for both Whites and Blacks. Maternal monitoring may be a salient influence for Blacks because more than half of Black children live in single-mother households compared to only $21 \%$ of White children (Vespa, Lewis, and Kreider 2013).

Parent-child communication appears to be another potential protective factor that can reduce victimization risk. Such communication can increase the child's support-seeking behavior when victimized, which can decrease their risk of victimization (Gentzler et al. 2005). However, parent-child communication has a main effect on victimization for White adolescents but does not have a similar effect for Black adolescents. Despite this, for Black adolescents, high levels of parent-child communication appeared to play a protective role in relation to the effects of delinquent friend influences for victimization. This finding is consistent with other studies, which reported that among Black youth, a high level of parent-child communication is negatively associated with risk behaviors (e.g., Sutton et al. 2014) and positively related to prosocial behavior (e.g., Connell and Prinz 2002). Parenting that is not controlling or overly intrusive in terms of adolescents' private worlds has been reported to be an effective way for parents to help their children develop less deviant and more positive peer-group interactions (Kakihara et al. 2010) possibly because such a strategy enhances rates of self-disclosure by adolescents (Soenens et al. 2006). Moreover, the lack of overly intrusive behavior might foster a level of independence and improved self-esteem in adolescents, which has been found to be negatively related with bullying perpetration and victimization. That is, individuals with higher self-esteem are less likely to be involved in bullying situations (O'Moore and Kirkham 2001). Future research might therefore consider whether the parent-child communication across Blacks and Whites differs in terms of the degree to which it typically intrudes into what adolescents consider to be their private lives and Black parents may have clearer boundaries in this respect than White parents.

Turning to perpetration, peer influence was a more prominent covariate. Greater delinquent friend activities and fewer positive peer relationships were associated with bullying, which supports previous studies (Espelage, Holt, and Henkel 2003; Haynie et al. 2001). Of note is that there were microsystem interactions evident here as well. For Blacks, parent-child communication made very little difference in perpetration when these adolescents had many delinquent friends, yet when these adolescents had lower numbers of delinquent friends, low parent-child communication was associated with less bullying of others. The reasons underpinning these effects are not easy to discern, 
and future research should seek to both replicate these results and to explore them further. The use of qualitative research methods may help clarify the ways in which parental communication, support, and treatment differ and how these are experienced.

A similar effect existed for Whites, with higher parent-child communication increasing the levels of bullying when the adolescent reported high numbers of delinquent peers. Possibly, for some Whites, they might have parents with permissive, or encouraging attitudes toward bullying, which can reinforce bullying behavior. High levels of older sibling communication also served to reduce the effects of delinquent peers when there were only low levels of delinquent peers present but increased levels of bullying when there were high levels of delinquent peers. Eslea and Smith (2000) reported that the presence of more siblings was associated with more use of bullying, although they did not document whether siblings were younger or older. In general, though, very little empirical evidence exists exploring the links between sibling interactions and bullying, and these results should be interpreted with caution given how small they are.

The ecological variables investigated in this study were also associated with bully, victim, and bullyvictim status. In addition to results mirroring those already discussed in relation to victimization and bullying, of interest were variables which were associated with the combined bully-victim status group. Having delinquent peers was associated with greater likelihood of being a bully-victim, while positive peer relations reduced it. This was true for all adolescents. Only among Whites did parental support and parental treatment reduce the likelihood of bully-victim status. For Blacks, mother's parental monitoring was the only family variable that was negatively associated with bully-victim status. Given the particularly high association between bully-victim status and maladjustment (Kowalski and Limber 2013; Mayes et al. 2014), interventions need to target this group, and our results speak to the combined importance of a positive peer climate and parental support in such efforts.

Finally, it is of note that some of our results are similar to some of the previous studies reporting that Black youth were more involved in perpetration (Carlyle and Steinman 2007; Wang, Iannotti, and Nansel 2009) and victimization (Rhee, Lee, and Jung 2017; Zhang, Musu-Gillette, and Oudekerk 2016) than their White peers. However, our results differed from Spriggs et al.'s (2007) study, which also relied on the Health Behavior in the School-aged Children data. These authors noted that Black adolescents reported significantly lower prevalence of victimization than their White counterparts. These results seem to indicate that there are important contextual factors at play. For example, the balance between majority and minority groups in specific schools can influence the amount of discriminatory aggression the respective groups report (Durkin et al. 2012). Such effects may help to explain differences in the prevalence of bullying and victimization across samples. On this score, prior research has demonstrated that racial differences exist in a number of different risk factors (Piquero 2015). The current research demonstrates that Blacks are more likely to be victimized than their White counterparts. The factors that lead to this are important to understand so as to best ensure that anti-bullying interventions are addressing the issues specific to each individual, group and/or culture. Reasons for bullying and type of bullying need additional consideration. Prior research has shown that Blacks who engage in racial bullying are not affected by interventions in school climate, but that this type of bullying did decrease in schools that had higher levels of diversity among teachers. Therefore, this demonstrates that programs that do not target the underlying issue for perpetrators or victims will not be able to provide sufficient or appropriate intervention and treatment. Given that bullying is deemed a 'serious public health problem,' a more thorough understanding of the factors associating with the subgroups of bullying involvement is needed. This study provides some confirmation in this regard.

Due to data constraints, certain factors relevant to the ecological model were unable to be explored, including measures reflecting community-level influences. Community violence is important in the development of socio-cognitive biases leading to bullying and victimization (Farver et al. 2005), and scholars have recommended considering their effects when seeking to understand bullying using the ecological model (Swearer and Doll 2001). A second limitation is that the data relied on adolescents' 
self-reports, and this may have resulted in issues associated with shared-method variance. Future research could seek to reduce this potential influence by obtaining parent-reports of family-level variables or perhaps peer-reports of bullying. Moreover, we limited our analysis to Black and White youth as they comprise the largest groups in the data we analyzed. Future work should replicate these findings across other racial/ethnic groups, such as, for example, Hispanics, Asian Americans, and American Indians. Also, this study did not consider any distinction between discriminatory and nondiscriminatory type of bullying, yet this can be the source of important differences across minority and majority racial groups (Durkin et al. 2012). Finally, the data were cross-sectional, thereby precluding any strong inference of causality between the variables investigated here.

\section{Conclusions}

One obvious implication of these results is the need for future research to investigate in more detail the nature of parental monitoring in White and Black families in the U.S. The notion of intrusion into what adolescents consider to be their private lives may be relevant (Kakihara et al. 2010) in part due to the ubiquity of smart-phone ownership and high levels of social media use among adolescents (Houghton et al. 2018; Przybylski and Weinstein 2017). These new technologies have opened up new ways in which adolescents can interact, while simultaneously allowing parents unprecedented access to their children's lives by presenting the opportunity for them to monitor discussions and interactions on social media and to tracking their child's location in real time (Gabriels 2016). Exploration of these issues with respect to the influence of parent and family-level variables on bullying and victimization is therefore recommended. Our results also highlight novel interactions between different systems described within the ecological model. Documenting these nuances and complexities is likely to be important for future advances in violence reduction among adolescents.

Our results also point to some similarities and yet some important differences regarding how aspects of the ecological model, both in isolation and interactively, relate to various aspects of bullying and victimization among Whites and Blacks. Our findings provide an important starting point for future theoretical development, empirical replication, and potentially different emphases for school-based preventive and intervention tactics moving ahead.

\section{Notes on contributors}

Jun Sung Hong is an Associate Professor in the School of Social Work at Wayne State University. He is currently the Co-Director of the Laboratory for the Study of Youth Inequality and Justice (in Virginia Tech). For the past several years, Hong has primarily conducted research on factors associated with bias-based bullying and peer victimization of racial/ethnic minority, immigrant, LGBTQ, juvenile justice involved and economically disenfranchised adolescents and young adults in the U.S. and in South Korea. He has also collaborated with scholars in South Korea, Taiwan, Sweden, Scotland, Switzerland, Spain, and Brazil on research projects.

Simon C. Hunter is a Senior Lecturer in the School of Psychological Sciences and Health at the University of Strathclyde (Glasgow, UK). He received his Ph.D. in Psychology from the University of Strathclyde in 2004 and has published primarily on bullying, screen-use, and psycho-social wellbeing among youth.

Jinwon Kim is a Senior Researcher in Institute for Social Welfare Studies at Sungkyunkwan University in Seoul, South Korea. His research interests include social adaptation and problems of adolescents and immigrant youth, individual well-being, changing family structure, positive effects of family activities, and quantitative research methods. Recently, Kim has primarily conducted research on factors associated with bullying and peer victimization of adolescents, and the developmental trajectories of adolescent well-being during a divorce process. He has also participated in various $\mathrm{R} \& \mathrm{D}$ projects on social welfare and has a several years of career as a social worker.

Alex R. Piquero is Ashbel Smith Professor of Criminology and Associate Dean of Graduate Programs in the School of Economic, Political and Policy Sciences at the University of Texas at Dallas and Professor of Criminology at Monash University in Melbourne Australia. He is also editor of Justice Evaluation Journal. His research interests include criminal careers, criminological theory, crime policy, evidence-based crime prevention, and quantitative research methods. He is consistently ranked among the most published and most cited criminologists in the world. He has 
received several research, teaching, and service awards and is Fellow of both the American Society of Criminology and the Academy of Criminal Justice Sciences. In 2014, he received The University of Texas System Regents' Outstanding Teaching Award and in 2018 he was inducted into The University of Texas System Academy of Distinguished Teachers. In 2019, he received the Academy of Criminal Justice Sciences Bruce Smith, Sr. Award for outstanding contributions to criminal justice.

Chelsey Narvey is a third year Ph.D. student in Criminology at the University of Texas at Dallas. Her research interests include criminological theory, corrections, and developmental/life-course criminology, and she does work at the intersection of corrections and life-course theory. She has published on telemedicine and the way it can be used in correctional settings. Some of her work can be found in the Journal of Correctional Healthcare, as well as in Aggression \& Violent Behavior. In 2019, she won the Distinguished Instruction by a Teaching Assistant Award in her school.

\section{References}

Aiken, Leona S., Stephen G. West, and Raymond R. Reno. 1991. Multiple Regression: Testing and Interpreting Interactions. Thousand Oaks, CA: Sage Publications.

Akers, Ronald L. 1998. Social Learning and Social Structure: A General Theory of Crime and Deviance. Boston, MA: Northeastern University Press.

Allen, Joseph P., Maryfrances Porter, Christy MacFarland, Kathleen Boykin McElhaney, and Penny Marsh. 2007. “The Relation of Attachment Security to Adolescents' Paternal and Peer Relationships, Depression, and Externalizing Behavior." Child Development 78 (4):1222-39. doi:10.1111/j.1467-8624.2007.01062.x.

Aspy, Cheryl B., Sara K. Vesely, Roy F. Ofman, Eleni Tolma, Sharon Rodine, Ladonna Marshall, and Janene Fluhr. 2012. "School-related Assets and Youth Risk Behaviors: Alcohol Consumption and Sexual Activity." Journal of School Health 82 (1):3-10. doi:10.1111/j.1746-1561.2011.00661.x.

Bauer, Nerissa S., Paula Lozano, and Frederick P. Rivara. 2007. “The Effectiveness of the Olweus Bullying Prevention Program in Public Middle Schools: A Controlled Trial.” Journal of Adolescent Health 40 (3):266-74. doi:10.1016/j. jadohealth.2006.10.005.

Belsky, Jay, Marian J. Bakermans-Kranenburg, and Marinus H. van IJzendoornm. 2002. "For Better and for Worse: Differential Susceptibility to Environmental Influences." Current Directions in Psychological Science 16 (6):300-04. doi:10.1111/j.1467-8721.2007.00525.x.

Birkland, Thomas A. and Regina G. Lawrence. 2009. “Media Framing and Policy Change after Columbine.” American Behavioral Scientist 52 (10):1405-25. doi:10.1177/0002764209332555.

Black, Sally A. and Ericka Jackson. 2007. "Using Bullying Incidence Density to Evaluate the Olweus Bullying Prevention Programme.” School Psychology International 28 (5):623-38. doi:10.1177/0143034307085662.

Bollmer, Julie M., Richard Milich, Monica J. Harris, and Melissa A. Maras. 2005. "A Friend in Need: The Role of Friendship Quality as A Protective Factor in Peer Victimization and Bullying." Journal of Interpersonal Violence 20 (6):701-12. doi:10.1177/0886260504272897.

Bradshaw, Catherine P., Christine W. Koth, Leslie A. Thorton, and Phillip J. Leaf. 2009. “Altering School Climate through School-wide Positive Behavioral Interventions and Supports: Findings from a Group-Randomized Effectiveness Trial." Prevention Science 10:100-15. doi:10.1007/s11121-008-0114-9.

Bronfenbrenner, Urie. 1977. “Toward an Experimental Ecology of Human Development.” American Psychologist 32 (7):513-37. doi:10.1037/0003-066X.32.7.513.

Bronfenbrenner, Urie. 1979. The Ecology of Human Development: Experiments by Nature and Design. Cambridge, MA: Harvard University Press.

Bronfenbrenner, Urie. 1994. “Ecological Models of Human Development.” Pp. 1643-47. in The International Encyclopedia of Education, $2^{\text {nd }}$ ed., edited by Torsten Husen and T. Neville Postlethwaite. New York: Elsevier Science.

Carlson, Karen Townsend. 2006. "Poverty and Youth Violence Exposure: Experiences in Rural Communities." Children and Schools 28 (2):87-96. doi:10.1093/cs/28.2.87.

Carlyle, Kellie E. and Kenneth J. Steinman. 2007. "Demographic Differences in the Prevalence, Co-Occurrence, and Correlates of Adolescent Bullying at School." Journal of School Health 77 (9):623-29. doi:10.1111/j.1746-1561.2007.00242.x.

Chapman, Paula L. and Ronald L. Mullis. 2000. "Racial Differences in Adolescent Coping and Self-Esteem." The Journal of Genetic Psychology 161 (2):152-60. doi:10.1080/00221320009596702.

Chaux, Enrique, Andres Molano, and Paola Podlesky. 2009. "Socio-Economic, Socio-Political and Socio-Emotional Variables Explaining School Bullying: A Country-wide Multilevel Analysis.” Aggressive Behavior 35 (6):520-29. doi:10.1002/ab.20320.

Connell, Christian M. and Ronald J. Prinz. 2002. "The Impact of Childcare and Parent-Child Interactions on School Readiness and Social Skills Development for Low-Income African American Children.” Journal of School Psychology 40 (2):177-93. doi:10.1016/S0022-4405(02)00090-0.

Conners-Burrow, Nicola A., Danya L. Johnson, Leanna Whiteside-Mansell, Lorraine McKelvey, and Regina A. Gargus. 2009. "Adults Matter: Protecting Children from the Negative Impacts of Bullying." Psychology in the Schools 46 (7):593-604. doi:10.1002/pits.20400. 
Currie, Candace, Cara Zanotti, Antony Morgan, Dorothy Currie, Margaretha de Looze, Chris Roberts, Otto R. Oddrun Samdal, F. Smith, and Vivian Barnekow. 2012. "Social Determinants of Health and Well-Being among Young People." in Health Behaviour in School-aged Children (HBSC) Study: International Report from the 2009/2010 Survey. Copenhagen: WHO Regional Office for Europe.

Durkin, Kevin, Kate A. Simon Hunter, Dermot Bergin Levin, Derek Heim, and Christine Howe. 2012. "Discriminatory Peer Aggression among Children as a Function of Minority Status and Group Proportion in School Context." European Journal of Social Psychology 42 (2):243-51. doi:10.1002/ejsp.870.

Eamon, Mary K. 2000. “The Effects of Poverty on Children's Socioemotional Development: An Ecological Systems Analysis." Social Work 46 (3):256-66. doi:10.1093/sw/46.3.256.

Elgar, Frank J., Wendy Craig, William Boyce, Antony Morgan, and Rachel Vella-Zarb. 2009. "Income Inequality and School Bullying: Multilevel Study of Adolescents in 37 Countries.” Journal of Adolescent Health 45 (4):351-59. doi:10.1016/j.jadohealth.2009.04.004.

Eliot, Megan, Dewey Cornell, Anne Gregory, and Xitao Fan. 2010. "Supportive School Climate and Student Willingness to Seek Help for Bullying and Threats of Violence." Journal of School Psychology 48 (6):533-53. doi:10.1016/j.jsp.2010.07.001.

Elliott, Delbert S. and Scott Menard. 1996. "Delinquent Friends and Delinquent Behavior: Temporal and Developmental Patterns." Pp. 28-67 in Delinquency and Crime: Current Theories, edited by J. David Hawkins, Alfred Blumstein, and David Farrington. Cambridge, MA: Cambridge University Press,

Elsaesser, Caitlin, Beth Russell, Christine McCauley Ohannessian, and Desmond Patton. 2017. "Parenting in A Digital Age: A Review of Parents' Role in Preventing Adolescent Cyberbullying." Aggression and Violent Behavior 35:62-72. doi:10.1016/j.avb.2017.06.004.

Eslea, Mike and Peter K. Smith. 2000. "Pupil and Parent Attitudes Towards Bullying in Primary Schools." European Journal of Psychology of Education 15 (2):207-19. doi:10.1002/ejsp.870.

Espelage, Dorothy L. 2004. “An Ecological Perspective to School-based Bullying Prevention.” Prevention Researcher 11 (3):3-6.

Espelage, Dorothy L., Melissa K. Holt, and Rachel R. Henkel. 2003. "Examination of Peer-Group Contextual Effects on Aggression during Early Adolescence.” Child Development 74 (1):205-20. doi:10.1111/1467-8624.00531.

Farver, Jo, M. Ann, Xu Yiyuan, Stefanie Eppe, Alicia Fernandez, and David Schwartz. 2005. "Community Violence, Family Conflict, and Preschoolers' Socioemotional Functioning." Developmental Psychology 41 (1):160-70. doi:10.1037/0012-1649.41.1.160.

Ferguson, Christopher J., Claudia San Miguel, John C. Kilburn, and Patricia Sanchez. 2007. "The Effectiveness of School-based Anti-Bullying Programs: A Meta-Analytic Review.” Criminal Justice Review 32 (4):401-14. doi:10.1177/0734016807311712.

Flaspohler, Paul D., Jennifer L. Elfstrom, Karin L. Vanderzee, Holli E. Sink, and Zachary Birchmeier. 2009. “Stand by Me: The Effects of Peer and Teacher Support in Mitigating the Impact of Bullying on Quality of Life." Psychology in the Schools 46 (7):636-49. doi:10.1002/pits.20404.

Gabriels, Katleen. 2016. “I Keep A Close Watch on This Child of Mine': A Moral Critique of Other-Tracking Apps.” Ethics and Information Technology 18 (3):175-84. doi:10.1007/s10676-016-9405-1.

Gaffney, Hannah, David P. Farrington, and Maria M. Ttofi. 2019. "Examining the Effectiveness of School-Bullying Intervention Programs Globally: A Meta-Analysis.” International Journal of Bullying Prevention 1 (1):14-31. doi:10.1007/s42380-019-0007-4.

Gentzler, Amy L., Josefina M. Contreras-Grau, Kathryn A. Kerns, and Barbara L. Weimer. 2005. "Parent-Child Emotional Communication and Children's Coping in Middle Childhood.” Social Development 14 (4):591-612. doi:10.1111/j.1467-9507.2005.00319.x.

Gladden, R. Matthew, Alana M. Vivolo-Kantor, Merle E. Hamburger, and Corey D. Lumpkin. 2014. Bullying Surveillance among Youths: Uniform Definitions for Public Health and Recommended Data Elements, Version 1.0. Atlanta, GA: National Center for Injury Prevention and Control, Centers for Disease Control and Prevention and U.S. Department of Education.

Hall, William. 2017. “The Effectiveness of Policy Interventions for School Bullying: A Systematic Review." Journal of the Society for Social Work and Research 8 (4):45-69. doi:10.1086/690565.

Hong, Jun Sung, Dorothy L. Espelage, Simon C. Hunter, and Paula Allen-Meares. 2018. "Integrating Multidisciplinary Social Science Theories and Perspectives to Understand School Bullying and Victimization." Pp. 109-20 in International Handbook on Aggression: Current Issues and Perspectives, edited by Jane L. Ireland, Phillip Birch, and Carol A. Ireland. New York: Routledge,

Hong, Jun Sung, Bee Ryou, and Alex R. Piquero. 2017. "Do Family-level Factors Associated with Bullying Perpetration and Peer Victimization Differ by Race? Comparing European American and African American Youth." Journal of Interpersonal Violence. doi:10.1177/0886260517714441.

Houghton, Stephen, Simon C. David Lawrence, Michael Rosenberg Hunter, Corrine Zadow, Lisa Wood, and Trevor Shilton. 2018. "Reciprocal Relationships between Trajectories of Depressive Symptoms and Screen Media Use during Adolescence." Journal of Youth and Adolescence 47 (11):2453-67. doi:10.1007/s10964-018-0901-y. 
Hughes, Diane, James Rodriguez, Emilie P. Smith, Deborah J. Johnson, Howard C. Stevenson, and Paul Spicer. 2006. "Parents' Ethnic-Racial Socialization Practices: A Review of Research and Directions for Future Study." Developmental Psychology 42 (5):747-70. doi:10.1037/0012-1649.42.5.747.

Jantzer, Vanessa, Johann Haffner, Peter Parzer, Franz Resch, and Michael Kaess. 2015. “Does Parental Monitoring Moderate the Relationship between Bullying and Adolescent Nonsuicidal Self-Injury and Suicidal Behavior? A Community-based Self-Report Study of Adolescents in Germany.” BMC Public Health 15 (583):583. doi:10.1186/ s12889-015-1940-x.

Juvonen, Jaana, Sandra Graham, and M A. Schuster. 2003. "Bullying among Young Adolescents: The Strong, the Weak, and the Troubled.” Pediatrics 112 (6):1231-37. doi:10.1542/peds.112.6.1231.

Kakihara, Fumiko, Lauree Tilton-Weaver, Margaret Kerr, and Hakan Stattin. 2010. "The Relationship of Parental Control to Youth Adjustment: Do Youths' Feelings about Their Parents Play a Role?" Journal of Youth and Adolescence 39 (12):1442-56. doi:10.1007/s10964-009-9479-8.

Kendrick, Kristin, Goran Jutengren, and Hakan Stattin. 2012. "The Protective Role of Supportive Friends against Bullying Perpetration and Victimization." Journal of Adolescence 35 (4):1069-80. doi:10.1016/j. adolescence.2012.02.014.

Kennedy, J H. and C E. Kennedy. 2004. “Attachment Theory: Implications for School Psychology.” Psychology in the Schools 41 (2):247-59. doi:10.1002/pits.10153.

Koo, D J., A A. Peguero, and Zahra Shekarkhar. 2012. "Gender, Immigration, and School Victimization.” Victims and Offenders 7 (1):77-96. doi:10.1080/15564886.2011.629773.

Kowalski, R M. and S P. Limber. 2013. "Psychological, Physical, and Academic Correlates of Cyberbullying and Traditional Bullying." Journal of Adolescent Health 53 (1):S13-S20. doi:10.1016/j.jadohealth.2012.09.018.

Larochette, A., A N. Murphy, and W M. Craig. 2010. "Racial Bullying and Victimization in Canadian School-Aged Children: Individual and School Level Effects.” School Psychology International 31 (4):389-408. doi:10.1177/ 0143034310377150 .

Lauritsen, J L., R J. Sampson, and J H. Laub. 1991. "The Link between Offending and Victimization among Adolescents." Criminology 29 (2):265-92. doi:10.1111/j.1745-9125.1991.tb01067.x.

Lee, C-H. and Juyoung Song. 2012. "Functions of Parental Involvement and Effects of School Climate on Bullying Behaviors among South Korean Middle School Students." Journal of Interpersonal Violence 27 (12):2437-64. doi:10.1177/0886260511433508.

Limber, Susan P., Maury Nation, Allison Tracy, Gary B. Melton, and Vicki Flerx. 2004. "Implementation of the Olweus Bullying Prevention Programme in the Southeastern United States." Pp. 55-79 in Bullying in Schools: How Successful Can Intervention Be? edited by Peter K. Smith, Debra Pepler, and Ken Rigby. Cambridge, UK: Cambridge University Press,

Mayes, Susan Dickerson, R. Raman Baweja, S L. Calhoun, Syed E., Farhat Mahr, and F. Siddiqui. 2014. "Suicide Ideation and Attempts and Bullying in Children and Adolescents. Psychiatric and General Population Samples." Crisis 35 (5):301-09. doi:10.1027/0227-5910/a000264.

Merrell, K W., B A. Gueldner, S W. Ross, and D M. Isava. 2008. "How Effective are School Bullying Intervention Programs? A Meta-Analysis of Intervention Research.” School Psychology Quarterly 23 (1):26-42. doi:10.1037/10453830.23.1.26.

Musu-Gillette, Lauren, Anlan Zhang, Ke Wang, Jizhi Zhang, and Barbara A. Oudekerk. 2019. Indicators of School Crime and Safety: 2018 (NCES 2019-047/NCJ 252571). Washington, DC: National Center for Education Statistics, U.S. Department of Education, and Bureau of Justice Statistics, Office of Justice Programs, U.S. Department of Justice.

O’Moore, M. and C. Kirkham. 2001. "Self-esteem and Its Relationship to Bullying behaviour." Aggressive Behavior 27:269-83. doi:10.1002/ab.1010.

Paternoster, Raymond, Robert Brame, Paul Mazerolle, and Alex Piquero. 1998. "Using the Correct Statistical Test for the Equality of Regression Coefficients.” Criminology 36 (4):859-66. doi:10.1111/j.1745-9125.1998.tb01268.x.

Piquero, A R. 2015. "Understanding Race/Ethnicity Differences in Offending across the Life Course: Gaps and Opportunities." Journal of Developmental and Life Course Criminology 1 (1):21-32. doi:10.1007/s40865-015-0004-3.

Przybylski, A K. and Netta Weinstein. 2017. "A Large-Scale Test of the Goldilocks Hypothesis: Quantifying the Relations between Digital-Screen Use and the Mental Well-Being of Adolescents." Psychological Science 28 (2):204-15. doi:10.1177/0956797616678438.

Rhee, Siyon, S-Y. Lee, and S-H. Jung. 2017. "Ethnic Differences in Bullying Victimization and Psychological Distress: A Test of an Ecological Model." Journal of Adolescence 60:155-60. doi:10.1016/j.adolescence.2017.07.013.

Roberts, Chris, J. Freeman, O. Samdal, C. W. Schnohr, M. E. de Looze, S. Nic Gabhainn, R. Iannotti, and M. Rasmussen. the International HBSC Study Group. 2009. "The Health Behaviour in School-aged Children (HBSC) Study: Methodological Developments and Current Tensions.” International Journal of Public Health 54 (S2):140-50. doi:10.1007/s00038-009-5405-9.

Sawyer, A L., C P. Bradshaw, and L M. O’Brennan. 2008. “Examining Ethnic, Gender, and Developmental Differences in the Way Children Report Being a Victim of 'bullying' on Self-Report Measures." Journal of Adolescent Health 43 (2):106-14. doi:10.1016/j.jadohealth.2007.12.011. 
Scherr, Tracey G. and Jim Larson. 2010. "Bullying Dynamics Associated with Race, Ethnicity, and Immigration Status." Pp. 223-34 in Handbook of Bullying in Schools: An International Perspective, edited by Shane R. Jimerson, Susan M. Swearer, and Dorothy L. Espelage. New York: Routledge,

Seals, Dorothy and Jerry Young. 2003. "Bullying and Victimization: Prevalence and Relationship to Gender, Grade Level, Ethnicity, Self-Esteem, and Depression.” Adolescence 38 (152):735-47.

Shetgiri, Rashmi, Hua Lin, and Glenn Flores. 2013. "Trends in Risk and Protective Factors for Child Bullying Perpetration in the United States." Child Psychiatry and Human Development 44 (1):89-104. doi:10.1007/s10578012-0312-3.

Soenens, Bart, Maarten Vansteenkiste, Koen Luyckx, and Luc Goossens. 2006. "Parenting and Adolescent Problem Behavior: An Integrated Model with Adolescent Self-Disclosure and Perceived Parental Knowledge as Intervening Variables." Developmental Psychology 42 (2):305-18. doi:10.1037/0012-1649.42.2.305.

Spriggs, A L., R J. Iannotti, T R. Nansel, and D L. Haynie. 2007. “Adolescent Bullying Involvement and Perceived Family, Peer and School Relations: Commonalities and Differences across Race/Ethnicity.” Journal of Adolescent Health 41 (3):283-93. doi:10.1016/j.jadohealth.2007.04.009.

Sutton, M Y., S M. Lasswell, Yzette Lanier, and K S. Miller. 2014. "Impact of Parent-Child Communication Interventions on Sex Behaviors and Cognitive Outcomes for Black/African-American and Hispanic/Latino Youth: A Systematic Review, 1988-2012." Journal of Adolescent Health 54 (4):369-84. doi:10.1016/j. jadohealth.2013.11.004.

Szapocznik, Jose and J. Douglas Coatsworth. 1999. “An Ecodevelopmental Framework for Organizing the Influences on Drug Abuse: A Developmental Model of Risk and Protection.” Pp. 331-66 in Drug Abuse: Origins and Interventions, edited by Meyer D. Glantz and Christine R. Hartel. Washington, DC: American Psychological Association,

Tenenbaum, L S., Kris Varjas, Joel Meyers, and Leandra Parris. 2011. “Coping Strategies and Perceived Effectiveness in Fourth through Eighth Grade Victims of Bullying.” School Psychology International 32 (3):263-87. doi:10.1177/ 0143034311402309.

Ttofi, M M. and D P. Farrington. 2011. "Effectiveness of School-based Programs to Reduce Bullying: A Systematic and Meta-Analytic Review.” Journal of Experimental Criminology 7 (1):27-56. doi:10.1007/s11292-010-9109-1.

Vespa, Jonathan, Jamie M. Lewis, and Rose M. Kreider. 2013. America's Families and Living Arrangements: 2012. Washington, DC: Government Printing Office. U. S. Bureau of the Census, Current Population Reports.

Wang, Jing, R J. Iannotti, and T R. Nansel. 2009. "School Bullying among Adolescents in the United States: Physical, Verbal, Relational, and Cyber." Journal of Adolescent Health 45 (4):368-75. doi:10.1016/j.jadohealth.2009.03.021.

Wei, H-S., J H. Williams, J-K. Chen, and H-Y. Chang. 2010. “The Effects of Individual Characteristics, Teacher Practice, and School Organizational Factors on Students' Bullying: A Multilevel Analysis of Public Middle Schools in Taiwan." Children and Youth Services Review 32 (1):137-43. doi:10.1016/j.childyouth.2009.08.004.

Wilson, William J. 1987. The Truly Disadvantaged: The Inner-City, the Underclass, and Public Policy. Chicago, IL: University of Chicago Press.

You, Sukkyung, Euikyung Kim, and Mirim Kim. 2014. “An Ecological Approach to Bullying in Korean Adolescents.” Journal of Pacific Rim Psychology 8 (1):1-10. doi:10.1017/prp.2014.1.

Zhang, Anlan, Lauren Musu-Gillette, and Barbara A. Oudekerk. 2016. Indicators of School Crime and Safety: 2015 (NCES 2016-079/NCJ 249758). Washington, DC: National Center for Education Statistics, U.S. Department of Education, and Bureau of Justice Statistics, Office of Justice Programs, U.S. Department of Justice. 